\title{
Effect of a health coaching self-management program for older adults with multimorbidity in nursing homes
}

This article was published in the following Dove Press journal:

Patient Preference and Adherence

4 July 2014

Number of times this article has been viewed

\author{
Yeon-Hwan Park',2 \\ HeeKyung Chang ${ }^{3}$ \\ 'College of Nursing, ${ }^{2}$ The Research \\ Institute of Nursing Science, Seoul \\ National University, Seoul, South \\ Korea; ${ }^{3}$ Seoul Women's College \\ of Nursing, Seoul, South Korea
}

\begin{abstract}
Background and aims: Although a growing number of older people are suffering from multimorbidity, most of the health problems related to multimorbidity can be improved by self-management. The aim of this study was to examine the effectiveness of a health coaching self-management program for older adults with multimorbidity in nursing homes.

Methods: Older adults with multimorbidity from one nursing home in Korea were randomly allocated to either an intervention group $(n=22)$ or conventional group $(n=21)$. Participants in the intervention group met face to face with the researchers twice a week for 8 weeks, during which time the researchers engaged them in goal setting and goal performance using the strategies in the health coaching self-management program. Regular care was provided to the other participants in the conventional group.

Results: Participants in the intervention group had significantly better outcomes in exercise behaviors $(P=0.015)$, cognitive symptom management $(P=0.004)$, mental stress management/ relaxation $(P=0.023)$, self-rated health $(P=0.002)$, reduced illness intrusiveness $(P<0.001)$, depression $(P<0.001)$, and social/role activities limitations $(P<0.001)$. In addition, there was a significant time-by-group interaction in self-efficacy $(P=0.036)$. According to the goal attainment scales, their individual goals of oral health and stress reduction were achieved.

Conclusion: The health coaching self-management program was successfully implemented in older adults with multimorbidity in a nursing home. Further research is needed to develop and evaluate the long-term effects of an intervention to enhance adherence to self-management and quality of life for older adults with multimorbidity.
\end{abstract}

Keywords: chronic diseases, nursing intervention, older adults, RCT

\section{Introduction}

With a growing number of older people suffering from multimorbidity, the demand for long-term care is growing worldwide. ${ }^{1}$ Multimorbidity in older people has been estimated to range from $55 \%-98 \%{ }^{2}$ An epidemic increase in multimorbidity has been reported in South Korea with $68.3 \%$ of older Koreans having multimorbidity. ${ }^{3}$ Most of the health problems related to multimorbidity can be prevented or delayed by selfmanagement. ${ }^{4}$ Various self-management support initiatives have been implemented to assist patients in optimizing the management of their health, including a focus on chronic disease self-management education programs. ${ }^{4}$ As such, self-management education programs are increasingly recognized not only as part of secondary prevention but also as a way of reducing the burden of chronic illnesses on individuals and the community. ${ }^{5}$

Despite the advancements in self-management support at policy and program levels, these initiatives tend to remain separate from mainstream health care and have
Correspondence: HeeKyung Chang Seoul Women's College of Nursing, 38 Ganhodae-Ro, Seodaemun-Gu, Seoul 120-742, South Korea

Tel $+8222287 \quad 1723$

Fax +8223958018

Email hchang@snjc.ac.kr 
had insufficient coordination for an effective and sustainable impact. ${ }^{6}$ Traditional self-management strategies that rely on education and persuasion have not been the most effective; thus, a shift in approach is needed. ${ }^{7}$ In addition, few studies have been conducted that investigated the efficacy of self-management on health outcomes particularly for nursing home residents. Although there may be arguments that self-management strategies have no place in nursing home residents, the need for such care for dependent older people in nursing homes has increased. ${ }^{8}$

Coaching in sports and business and more recently in nursing has been reported as successful in motivating people toward personal and professional goal attainment. ${ }^{9}$ Health coaching is the practice of health education and health promotion within a coaching context to enhance the well-being of individuals and to facilitate the achievement of their health-related goals. ${ }^{4}$

Especially, health coaching provided by nurses has shown promise as a strategy for facilitating behavior change that can lead to improvement in older patients with chronic illnesses. ${ }^{10}$ Based on a humanistic and holistic perspective, health coaching is compatible with nursing ideals, and a coaching strategy holds promise for helping older adults to achieve their health goals. ${ }^{11}$ Coaching by nurses may motivate older adults with chronic illnesses to move forward, to take action toward making lifestyle changes, and to increase their understanding. ${ }^{9}$ Coaching could be very effective in encouraging, inspiring, and empowering patients to reach their maximum health potential, but to be effective as coaches, nurses need training in coaching strategies. ${ }^{11}$ Thus, health coaching is an expected competency for nurses through which older adults can promote their self-management skills, prevent complications, lessen their health care costs, and appreciate a better quality of life. ${ }^{11,12}$ The benefits of coaching, however, have been reported mostly anecdotally, and coaching research is in its infancy.

In this study, therefore, we examined the effects of an 8-week health coaching self-management program (HCSMP) on self-care management behaviors, self-efficacy, health status, and individual goal setting and attainment.

\section{Methods}

\section{Study design}

This study was designed as a randomized controlled trial comparing health coaching on self-management with conventional care. The unit of randomization was an individual older person with multimorbidity, because the intervention is posited to exert its effects primarily by affecting participant attitudes, self-efficacy, and behaviors. ${ }^{13}$ The effects of the HCSMP were evaluated on the self-management behaviors, self-efficacy, and health status, with the intervention group receiving twice weekly group-level activities and an individual approach to self-management during 8 weeks and the conventional group receiving conventional care.

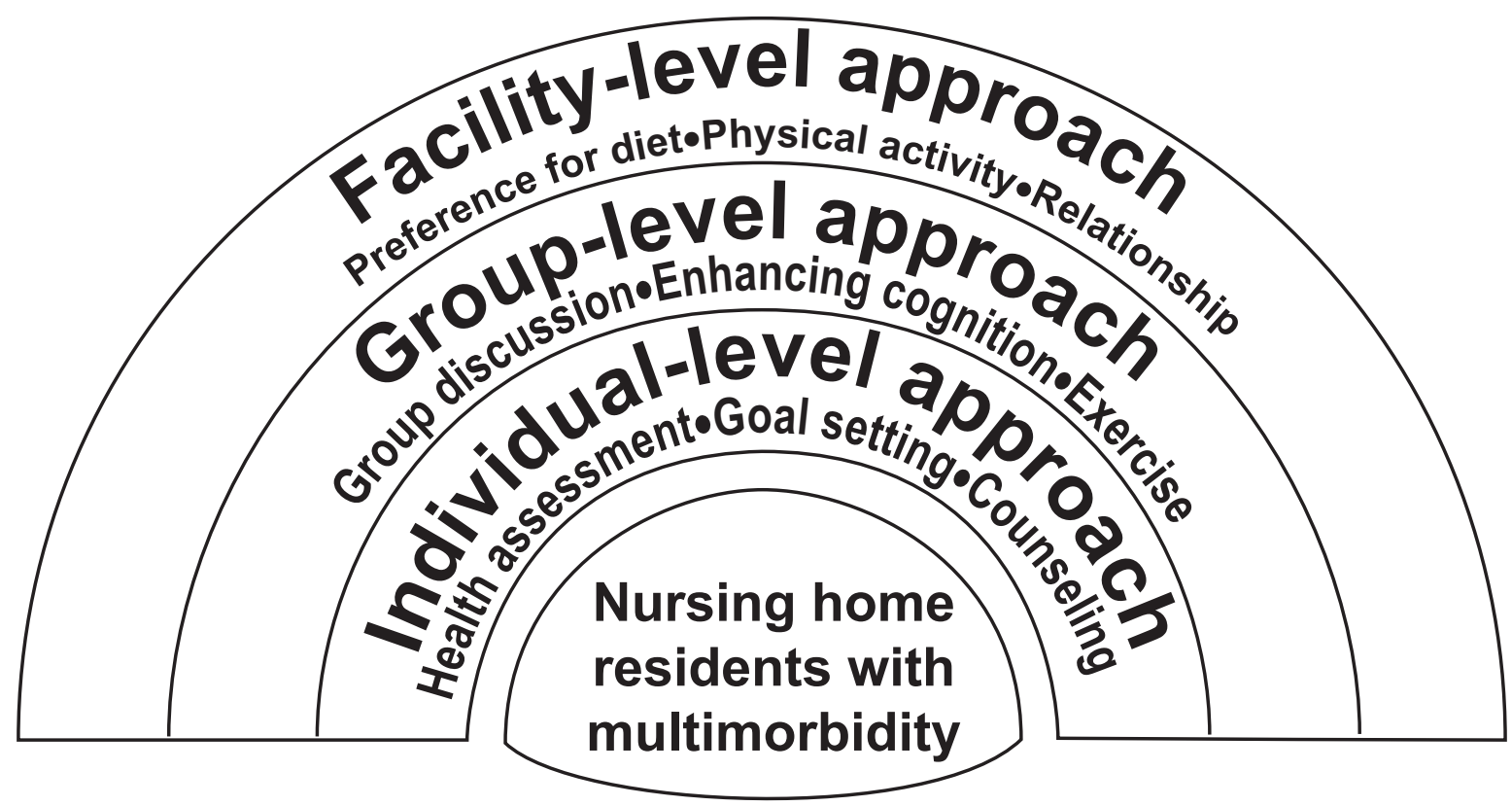

Figure I Structure of the HCSMP.

Abbreviation: HCSMP, health coaching self-management program. 


\section{Study procedure}

The study was approved by the Seoul National University institutional review board. Participants were recruited according to certain guidelines. First, the first author explained the purpose and specific process of this study to the director and chief manager in one nursing home in South Korea. Second, all older people residing in the nursing home were identified $(n=112)$. If the older adults indicated they were willing to participate, research assistants determined whether they fit the inclusion criteria. The inclusion criteria were: 1) age $\geq 65$ years; and 2) diagnosis of two or more chronic diseases within 1 year prior to the study. The exclusion criteria were an inability to understand and participate in the program process. Finally, participants $(\mathrm{n}=50)$ who fit the inclusion criteria were randomly assigned either to the intervention group ( $\mathrm{n}=25)$, or to the conventional group $(\mathrm{n}=25)$ (Figure 2$)$. All participants gave their written informed consent.

\section{Randomization and allocation concealment}

Randomization was stratified to ensure that each arm contained a similar ratio of male elderly to female elderly. Then, a statistician independently generated random sequences for 25 people in each group using the Randomizer form to create sealed opaque envelopes and delivered them to our research team. Participants were randomized to intervention care with the HCSMP or to conventional care in the nursing home, by sealed and opaque envelopes. With this allocation list, when the baseline data were completed for each participant, enrollment staff assigned the random allocation. Baseline outcomes were obtained before randomization and, therefore, were free of any assignment-related bias. Two research team members delivering the HCSMP were necessarily unblinded. To reduce any influence of the researcher on the outcome measurements, outcome data were collected by nursing home staff nurses at a different place and time from the delivery of the intervention. Random assignments were concealed from those staff nurses entering the outcome data and recorded in a separate password-protected database accessed from a separate computer. Data sets for the statistical outcome analysis did not show which set was from the conventional or the intervention group.

\section{Intervention: HCSMP}

The HCSMP was designed for older nursing home residents to explore their health status and apply self-management strategies to achieve their individual goals based on their needs. ${ }^{14}$ Based on the health coaching strategies presented, HCSMP was a whole-of-facility approach to improve care outcomes. It was systematized as three major categories, including the individual-level approach, the group-level approach, and the facility-level approach. The major components of the program were group health education and group exercise in the group-level approach and individual counseling for goal setting in the individual-level approach. ${ }^{4,14} \mathrm{Then}$, the categories consisted of: individual health assessment; goal setting and counseling; group discussion; enhancing cognition activities; exercise sessions; and an activity to encourage the facility's cooperation (Figure 1). The specific contents of the group exercise were validated by a sports exercise specialist based on the frailty of older adults in nursing homes. Finally, the specific protocol of the program was modified and confirmed (Table 1).

\section{Group-level approach: group discussion, enhancing cognition activities, and exercise}

The structured group health education was offered to the nursing home residents once a week for 8 weeks on every Monday. The health education focused on providing adequate knowledge and motivating self-management behaviors. The research team developed materials suitable for older adults and used unique teaching approaches to help older adults learn about their diseases and their management strategies. Each session lasted approximately 1 hour and was delivered in a seminar room at the nursing home by pairs of research team members, who were geriatric nurse specialists and trained to provide health coaching strategies. The topics of each session are listed in Table 1. Each session started with a short introduction to the topic and focused on the group discussion to share personal experiences associated with the topic for that session, followed by physical activities to enhance their cognition and body movements. The exercise, separate from the group health education, was provided for 8 weeks on every Thursday after a week of preliminary instruction. The 1-hour period of exercise consisted of stretching, hands and feet exercise, and joints movement training.

\section{Individual-level approach: health assessment, goal setting, and counseling}

Each participant received eight face-to-face coaching sessions over the intervention period. While there was no preset time frame for each health coaching session, it was anticipated that the duration of each session would be approximately 20 minutes. Prior to every group activity, individual counseling for goal setting by trained research team members was done to encourage the initiation and maintenance of self-management behaviors, and to help goal 


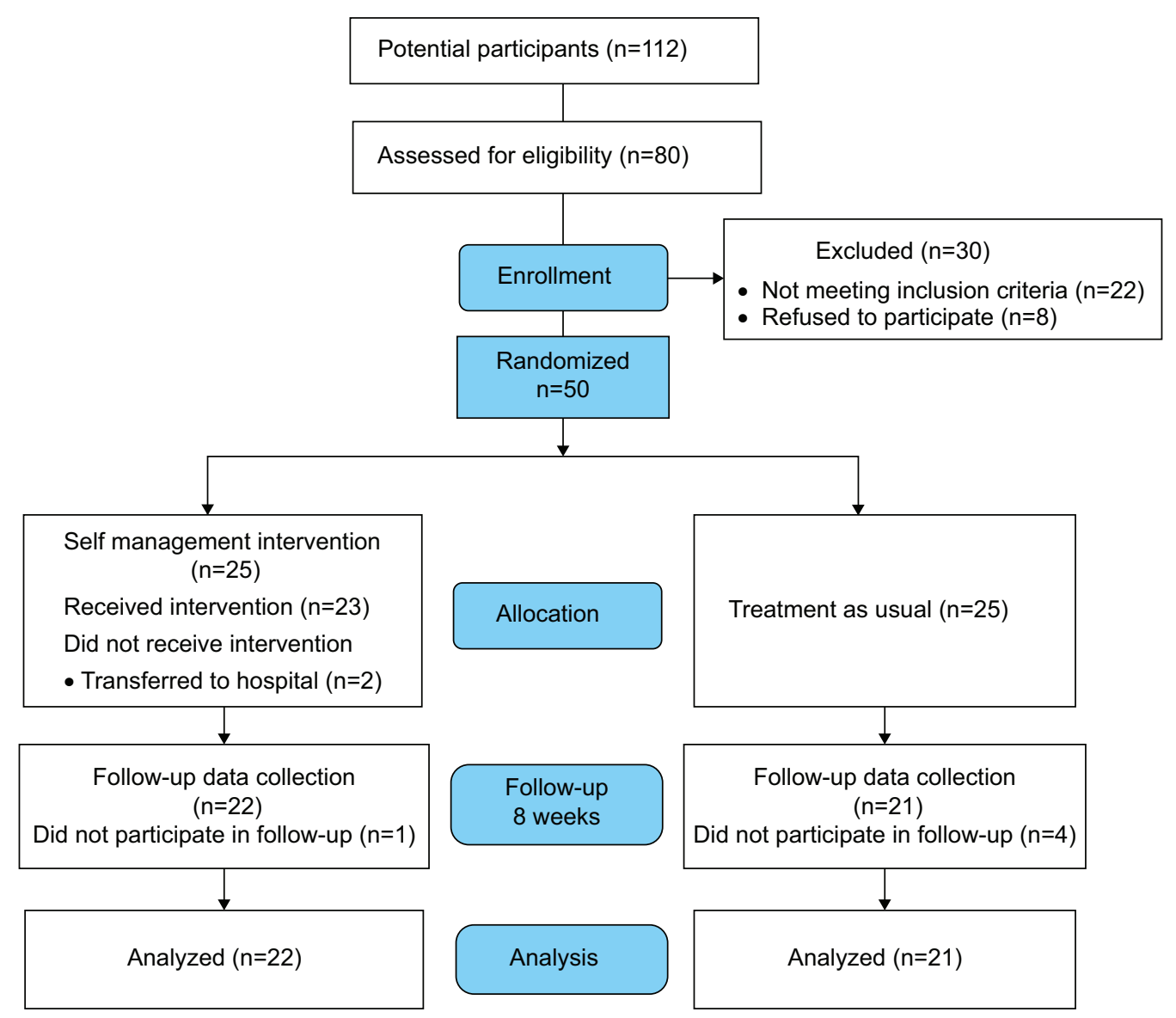

Figure 2 Flow chart for randomized trial.

setting. It took 30 minutes for each participant and was done in the patient's room at the nursing home. Especially, goal setting and counseling were provided on an individual basis because each self-management goal was different based on the resident's needs and motivation. Older people are more likely to benefit from a series of health education sessions followed by tailored feedback from the counselor. ${ }^{15}$ Some examples of these individualized health goals are presented in Table 2.

\section{Facility-level approach}

The facility-level approach was designed to facilitate and support participants' individual endeavor to achieve their health goals. ${ }^{4,14}$ The principal investigator had several meetings with the director and chief manager of the facility. A proposal to the facility including discussed issues in previous meetings was submitted (Table 1).

\section{Training of the research team}

To apply accurate health coaching strategies based on HCSMP, the research team developed a standardized training guide that specified the methodology, data collection and entry, and self-management protocol with a health coaching attitude. The principal investigator conducted the training sessions for the research team, consisting of geriatric nurse practitioners. Two experts in both geriatric nursing and motivational interviewing held mock interviews with the investigators and validated the counseling process and then modified the counseling scenarios for the investigators. The four research team members were responsible for the individual level approach, including health assessment, goal setting, and counseling. Meanwhile, four staff nurses working at the nursing home helped with the intervention process along with the research team during group sessions, such as the health discussions, activities for enhancing cognition, and exercises for participants. To encourage the sustained participation of residents, we provided adequate reimbursement to the staff including incentives or off-duty pay.

\section{Conventional group}

Participants in the conventional group were asked to maintain their regular lifestyle including dietary and exercise habits for 


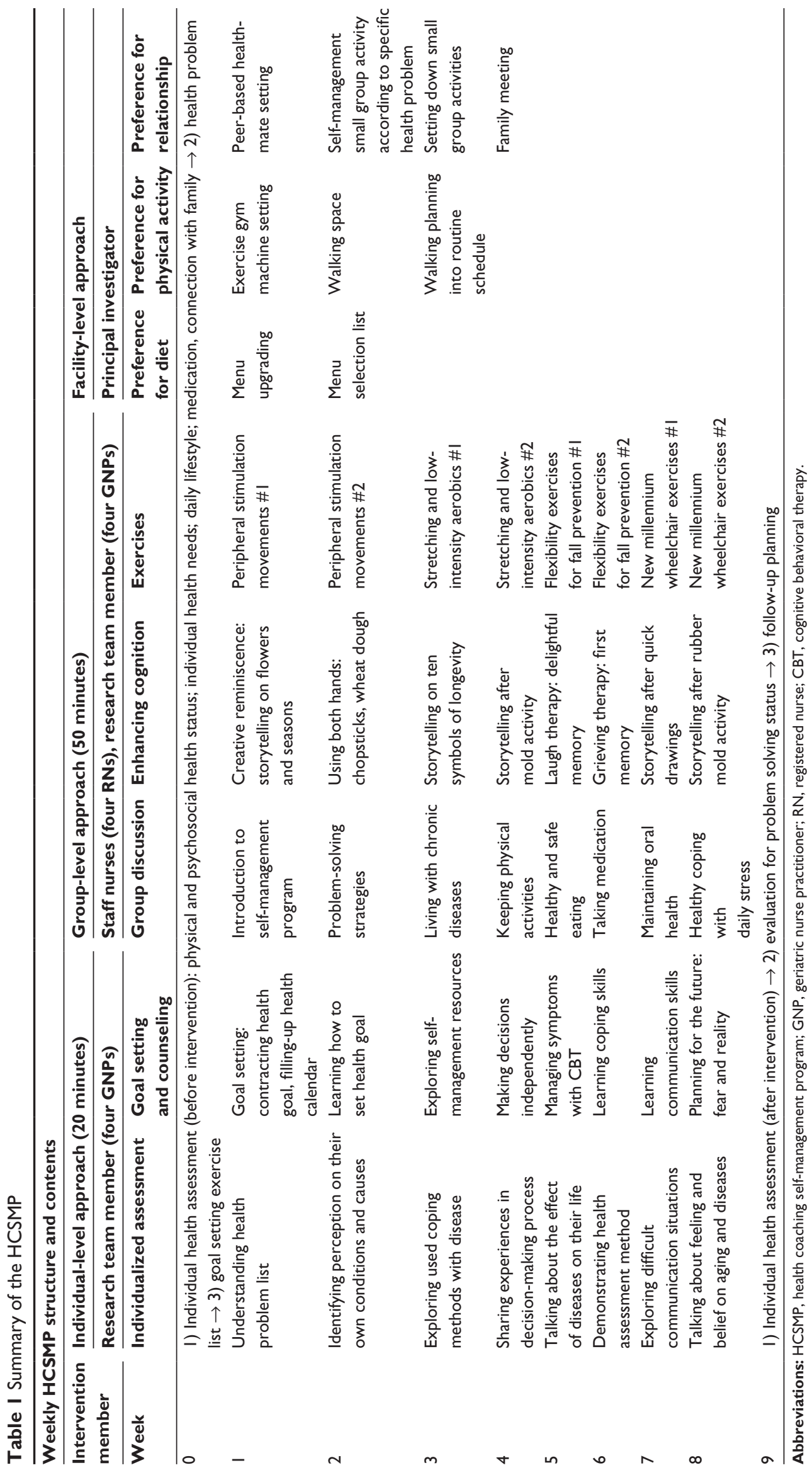


Table 2 Sample goal statements and GAS

\begin{tabular}{|c|c|c|c|c|c|}
\hline \multirow[t]{3}{*}{ Goal attainment level } & \multirow[t]{3}{*}{ Score } & \multicolumn{4}{|l|}{ Goal areas } \\
\hline & & Goal I & Goal 2 & Goal 3 & Goal 4 \\
\hline & & Oral health & Stress reduction & Physical activity & Healthy diet \\
\hline & & $\begin{array}{l}\text { I will brush my teeth and gums } \\
\text { three times a day for myself. }\end{array}$ & $\begin{array}{l}\text { I will find some time and } \\
\text { energy for recreational } \\
\text { activities once per week. }\end{array}$ & $\begin{array}{l}\text { I will establish a regular, } \\
\text { routine fitness program } \\
\text { three times per week. }\end{array}$ & $\begin{array}{l}\text { I will increase intake of } \\
\text { fruits and vegetables by } \\
\text { one serving per day. }\end{array}$ \\
\hline $\begin{array}{l}\text { Much better than } \\
\text { expected }\end{array}$ & +2 & $\begin{array}{l}\text { I brushed my teeth and gums } \\
\text { more than four times a day } \\
\text { for myself. }\end{array}$ & $\begin{array}{l}\text { I reserved some time and } \\
\text { energy for recreational } \\
\text { activities several times } \\
\text { each week. }\end{array}$ & $\begin{array}{l}\text { I exercised more than } \\
\text { four to five times } \\
\text { per week. }\end{array}$ & $\begin{array}{l}\text { I increased intake of fruits } \\
\text { and vegetables to more } \\
\text { than two servings } \\
\text { per day. }\end{array}$ \\
\hline $\begin{array}{l}\text { Somewhat better than } \\
\text { expected }\end{array}$ & +1 & $\begin{array}{l}\text { I brushed my teeth and gums } \\
\text { four times a day for myself. }\end{array}$ & $\begin{array}{l}\text { I reserved some time and } \\
\text { energy for recreational } \\
\text { activities more than once } \\
\text { per week. }\end{array}$ & $\begin{array}{l}\text { I exercised four to } \\
\text { five times per week. }\end{array}$ & $\begin{array}{l}\text { I increased intake of fruits } \\
\text { and vegetables by two } \\
\text { servings per day. }\end{array}$ \\
\hline $\begin{array}{l}\text { The expected level of } \\
\text { attainment }\end{array}$ & 0 & $\begin{array}{l}\text { I brushed my teeth and gums } \\
\text { three times a day for myself. }\end{array}$ & $\begin{array}{l}\text { I reserved some time and } \\
\text { energy for recreational } \\
\text { activities once per week. }\end{array}$ & $\begin{array}{l}\text { I established a regular, } \\
\text { routine fitness program } \\
\text { three times per week. }\end{array}$ & $\begin{array}{l}\text { I increased intake of fruits } \\
\text { and vegetables by one } \\
\text { serving per day. }\end{array}$ \\
\hline $\begin{array}{l}\text { Somewhat less than } \\
\text { expected }\end{array}$ & -1 & $\begin{array}{l}\text { Brushing less than three times } \\
\text { a day for myself. }\end{array}$ & $\begin{array}{l}\text { No change in time and } \\
\text { energy resources related } \\
\text { to recreation. }\end{array}$ & $\begin{array}{l}\text { Exercise less than three } \\
\text { times per week. }\end{array}$ & $\begin{array}{l}\text { No change in fruit and } \\
\text { vegetable intake. }\end{array}$ \\
\hline Much less than expected & -2 & $\begin{array}{l}\text { Brushing less than two times } \\
\text { a day for myself. }\end{array}$ & $\begin{array}{l}\text { Less time and energy } \\
\text { resources reserved for } \\
\text { recreation each week. }\end{array}$ & Very little or no exercise. & $\begin{array}{l}\text { Decreased fruit and } \\
\text { vegetable intake. }\end{array}$ \\
\hline
\end{tabular}

Abbreviation: GAS, Goal Attainment Scaling.

8 weeks until they were reexamined. The conventional group members received group-based education and participated in exercise sessions from the HCSMP 6 months later than that of the intervention groups.

\section{Outcome measurements}

Descriptive variables and outcomes were measured by face-to-face interview at baseline and after the completion of the intervention. Outcome measures, selected to evaluate the hypotheses, consisted of major three categories, selfmanagement behaviors, self-efficacy, and health status, and 42 items from the Chronic Disease Self-Management Program Questionnaire (CDSMPQ). ${ }^{16}$ In addition, health goal setting and attainment scales were used with the intervention participants only.

\section{CDSMPQ}

The CDSMPQ ${ }^{16}$ was used to measure outcomes focused on self-management behaviors, self-efficacy, and health status. The questionnaire conducted for this study was translated into Korean and verified by the authors and a bilingual expert and contains 70 items distributed in three dimensions: selfmanagement behaviors; self-efficacy; and health status. The questionnaire was administered in person by trained nursing home staff nurses.

\section{Goal Attainment Scaling (GAS)}

The methods used in this study were similar to those of other studies. ${ }^{17}$ The GAS was rated using a 5-point scale where 0 is the expected level of attainment if the older participant received the intended intervention program. In addition, +1 represents "somewhat better than expected" level of attainment, while +2 represents "much better than expected" level. Also, -1 represents "somewhat less than expected" level of attainment and -2 , "much less than expected". A list of the four top priority goals were identified from the goal-setting procedure described above, and a "statement of expected outcome" was determined for each goal to identify the 0 score. An example is presented in Table 2 . The elderly baseline score for each goal was set as -1, unless they could not have been at a worse level for that goal, in which case they scored $-2 .{ }^{17}$ The GAS levels were rated by an independent research assistant.

\section{Statistical analysis}

The sample size for the analysis was 43 (22 in the intervention group and 21 in the conventional group), which is sufficient to detect a small-moderate standardized effect size using a twotailed significance test with a power of $80 \%$ and an alpha level of 0.05. Data were analyzed using SPSS version 18.0 (SPSS Inc., Chicago, IL, USA). ${ }^{18}$ The baseline data of the two groups were compared using independent samples $t$-test for continuous 
data and Pearson's chi-squared test for categorical variables. For hypotheses testing, both a repeated-measure analysis of variance as well as $t$-tests were used on the intervention group and time as self-management behaviors, self-efficacy, and health status. The significance of group $\times$ time interaction was used to evaluate the effectiveness of the intervention.

\section{Results}

\section{Flow of participants through the trial}

The flow of participants through the trial is shown in Figure 2. A total of 80 nursing home residents were eligible to participate in the health coaching self-management intervention. Of those, 50 older adults (20.9\% male) were enrolled in the study. The 50 older adults were randomly assigned either to the intervention group $(n=25)$ or to the conventional group $(n=25)$. As can be seen in Figure 1, relatively few participants (14\%) dropped out after inclusion. Of the seven older people who did not complete the preintervention questionnaire, two withdrew from the study just after randomization because they were transferred to the hospital with pneumonia. One participant in the intervention group and four in the conventional did not return the postintervention questionnaire; one wrote that the study did not meet his expectations. The other four gave no specific reasons. The seven dropouts did not differ significantly from the other participants at baseline.

During the intervention period, two older adults in the intervention group (retention rate, 92.0\%) and four in the conventional group were lost to follow-up. The mean number of sessions attended was 7.4 (standard deviation =1.2), and 22 participants attended more than $90 \%$ of their sessions. One sample from the intervention group was excluded from analysis because of missing data. Finally, data were analyzed from 22 older adults in the intervention group and from 21 in the conventional group.

\section{Baseline characteristics}

Most participants were women (79.1\%), and one-third had a spouse $(32.6 \%)$. The mean age was 77.6 years (standard deviation $=6.5$; range $62-88$ years $)$. As shown in Table 3 , no significant differences in the basic participant characteristics between the two groups were found at baseline. In addition, no group differences were found on any of the outcome variables.

\section{Comparison of outcome variables after the 8-week intervention}

The HCSMP significantly improved all the outcomes for self-management behavior except for communication with health care professionals (Table 4).

\section{Self-management behaviors}

A significant interaction between the groups (health coaching self-management intervention and conventional) by time (from baseline to 8 weeks later) was found in: exercise behaviors $(P<0.001)$; cognitive symptom management $(P=0.044)$; and mental stress management $(P=0.047)$. Participants in the intervention had greater self-management behaviors than those in the conventional group, and exercise behaviors $(P=0.015)$, cognitive symptom management $(P=0.004)$, and mental stress management/relaxation $(P=0.023)$ significantly increased when comparing baseline to 8 weeks later for only the participants in the intervention group (Table 4).

\section{Self-efficacy}

Participants in the intervention group showed significant improvement in self-efficacy compared to those in the conventional group $(P=0.046)$. In addition, there was a significant time-by-group interaction in self-efficacy $(P=0.036)$ (Table 4).

\section{Health status}

Participants in the intervention group had significantly better self-rated health $(P=0.002)$ and reduced illness intrusiveness $(P<0.001)$, depression $(P<0.001)$, and social/role activities limitations $(P<0.001)$. A significant interaction between the groups by time was found in pain severity $(P=0.001)$ and social/role activities limitations $(P=0.008)$. Otherwise, the outcome variables - such as fatigue $(P=0.703)$, energy $(P=0.063)$, shortness of breath $(P=0.094)$, disability $(P=0.383)$, and health distress $(P=0.757)$ - showed no significant changes (Table 4).

\section{Success in self-management goal setting and attainment}

The four clinical tasks for goal setting that were particularly relevant to self-management behaviors include oral health, stress reduction, physical activity, and healthy diet (Table 2). All participants in the intervention group completed the GAS throughout the intervention period. The scores on the GAS showed that the participants reported that their individual goals were achieved in oral health (score $=1.5$ ) and stress reduction ( score $=0.3$ ); otherwise, physical activity and healthy diet area did not reach the expected goals (Figure 3).

\section{Discussion}

The HCSMP was successfully implemented improving the self-management behaviors, self-efficacy, and health status 
Table 3 Baseline demographic and clinical characteristics and outcome variables from health coaching self-management intervention

\begin{tabular}{|c|c|c|c|}
\hline Characteristics & $\begin{array}{l}\text { Intervention group } \\
(\mathrm{n}=\mathbf{2 2}) \mathrm{n}(\%)\end{array}$ & $\begin{array}{l}\text { Conventional group } \\
(n=21) n(\%)\end{array}$ & $\chi^{2}$ or $P$-value \\
\hline \multicolumn{4}{|l|}{ Sex } \\
\hline Female & $19(86.3)$ & $15(7 \mid .4)$ & 0.325 \\
\hline \multicolumn{4}{|l|}{ Diagnosis } \\
\hline Stroke & $16(72.7)$ & $15(7 \mid .4)$ & 0.140 \\
\hline Parkinson's disease & I (4.6) & $5(23.8)$ & \\
\hline Dementia & $5(22.7)$ & I (4.8) & \\
\hline \multicolumn{4}{|l|}{ Spouse } \\
\hline Yes & $6(27.3)$ & $8(40.0)$ & 0.356 \\
\hline \multirow[t]{2}{*}{ No } & $17(72.7)$ & $13(60.0)$ & \\
\hline & Mean (SD) & Mean (SD) & $P$-value \\
\hline \multicolumn{4}{|l|}{ Measures } \\
\hline Age (years) & $77.3(7.0)$ & $78.0(6.2)$ & 0.754 \\
\hline Years of education & $5.5(4.9)$ & $7.9(6.2)$ & 0.184 \\
\hline \multicolumn{4}{|l|}{ Self-management behaviors } \\
\hline Exercise behaviors & $33.4(26.2)$ & $49.3(29.7)$ & 0.070 \\
\hline Cognitive symptom management & $7.1(4.5)$ & $8.4(3.5)$ & 0.281 \\
\hline Mental stress management/relaxation & $\mathrm{I} .3(0.5)$ & $1.6(0.5)$ & 0.050 \\
\hline $\begin{array}{l}\text { Communication with health care } \\
\text { professionals }\end{array}$ & $3.7(2.0)$ & $4.5(2.7)$ & 0.245 \\
\hline \multicolumn{4}{|l|}{ Self-efficacy } \\
\hline Six item chronic disease self-efficacy & $4.6(2.5)$ & $7.0(3.0)$ & 0.576 \\
\hline \multicolumn{4}{|l|}{ Health status } \\
\hline Self-rated health & $3.4(0.7)$ & $3.4(0.9)$ & 0.909 \\
\hline Illness intrusiveness rating & $45.7(23.3)$ & $42.1(21.6)$ & 0.599 \\
\hline Fatigue visual numeric & $4.1(1.5)$ & $4.5(2.0)$ & 0.483 \\
\hline Energy/fatigue & $9.8(2.1)$ & I0.I (3.3) & 0.787 \\
\hline Pain visual numeric & $3.7(1.8)$ & $4.3(2.5)$ & 0.365 \\
\hline Pain severity/interference & $8.1(4.1)$ & $9.2(4.3)$ & 0.419 \\
\hline Shortness of breath visual numeric & $2.0(2.3)$ & $0.9(1.8)$ & 0.105 \\
\hline Eight item HAQ-disability & $12.2(5.7)$ & |3.I (6.3) & 0.602 \\
\hline Health distress & $1.9(1.0)$ & $2.4(0.9)$ & 0.083 \\
\hline PHQ-9 (depression) & $8.7(5.9)$ & $8.0(5.9)$ & 0.688 \\
\hline Social/role activities limitations & $3.1(0.8)$ & $2.8(1.4)$ & 0.311 \\
\hline
\end{tabular}

Abbreviations: SD, standard deviation; HAQ, Health Assessment Questionnaire; PHQ, Patient Health Questionnaire.

of the participants in the intervention group. Additionally, participants reported a high level of goal achievement. Our results are consistent with previous studies for older adults with multimorbidity; they support that health coaching intervention enhanced residents' participation in intervention programs, resulting in a significant increase in their self-efficacy and self-management behaviors. ${ }^{19}$

This study has several strengths. First, the participants were randomly assigned. Second, the intervention addressed multilevel approaches among individual, group, and facility levels related to self-management/functional limitations in nursing home residents with multimorbidity. Third, this study represents a rigorous clinical trial for a health coaching program in a nursing home. It is surprising that selfmanagement interventions for nursing home residents have not been extensively documented. Nursing home residents might be more vulnerable to poor self-management of chronic diseases due to disease burden, learned helplessness, cheap food due to economic reasons, lack of opportunity to exercise, poor cognition, and high rates of depression. ${ }^{20-22}$ Although self-management is particularly needed for nursing home residents in Korea, it could be argued that self-management strategies have no place in nursing homes on the grounds that nursing staffs are available because family support for care is no longer accessible as seen in community-dwelling older adults. ${ }^{8}$

Notably, there were no improvements in communication with health care professionals, fatigue, pain, shortness of breath, and health distress in older adults. When it comes to communication with health professionals, residents were supposed to see medical doctors on a regular basis in the nursing home; however, residents could not have a chance to see doctors on a regular basis in reality despite their needs. In addition, there simply aren't enough health care 
Table 4 Changes in self-management and health status variables from baseline to 8 weeks follow-up

\begin{tabular}{|c|c|c|c|c|c|c|}
\hline & $\begin{array}{l}\text { Baseline } \\
\text { mean (SD) }\end{array}$ & $\begin{array}{l}\text { 8th week } \\
\text { mean (SD) }\end{array}$ & $\begin{array}{l}\text { Mean } \\
\text { difference }\end{array}$ & $P$-value & $\begin{array}{l}\text { Effect } \\
\text { size }(d)\end{array}$ & $\begin{array}{l}\text { Group } \times \text { time } \\
P \text {-value }\end{array}$ \\
\hline \multicolumn{7}{|l|}{ Self-management behavior } \\
\hline Exercise behaviors & & & & & 0.754 & $<0.00 I^{* *}$ \\
\hline Conventional group & $49.3(29.7)$ & $43.6(25.9)$ & -5.7 & 0.365 & & \\
\hline Intervention group & $33.4(26.2)$ & $46.4(31.0)$ & 13.0 & $0.015^{*}$ & & \\
\hline Cognitive symptom management & & & & & 0.095 & $0.044^{*}$ \\
\hline Conventional group & $8.4(3.5)$ & $8.6(3.6)$ & 0.2 & 0.866 & & \\
\hline Intervention group & $7.1(4.5)$ & $10.5(4.2)$ & 3.4 & $0.004 * *$ & & \\
\hline Mental stress management/relaxation & & & & & 0.057 & $0.047^{*}$ \\
\hline Conventional group & $1.6(0.5)$ & $\mathrm{I} .5(0.3)$ & -0.1 & 0.756 & & \\
\hline Intervention group & $1.3(0.5)$ & $2.4(0.7)$ & I.I & $0.023^{*}$ & & \\
\hline $\begin{array}{l}\text { Communication with health care } \\
\text { professionals }\end{array}$ & & & & & 0.028 & $0.28 \mathrm{I}$ \\
\hline Conventional group & $4.5(2.7)$ & $4.1(3.0)$ & -0.4 & 0.514 & & \\
\hline Intervention group & $3.7(2.0)$ & $4.1(1.9)$ & 0.4 & 0.346 & & \\
\hline \multicolumn{7}{|l|}{ Self-efficacy } \\
\hline 6-item chronic disease self-efficacy & & & & & 0.018 & $0.036 *$ \\
\hline Conventional group & $28.0(11.7)$ & $28.3(13.7)$ & 0.3 & 0.581 & & \\
\hline Intervention group & $27.5(10.1)$ & $30.6(11.5)$ & 3.1 & $0.046 *$ & & \\
\hline \multicolumn{7}{|l|}{ Health status } \\
\hline Self-rated health & & & & & 0.126 & 0.087 \\
\hline Conventional group & $3.4(0.9)$ & $3.3(1.0)$ & -0.1 & 0.680 & & \\
\hline Intervention group & $3.4(0.7)$ & $2.8(0.6)$ & -0.6 & $0.002 * *$ & & \\
\hline Illness intrusiveness rating & & & & & 0.002 & 0.801 \\
\hline Conventional group & $42.1(21.6)$ & $65.5(17.0)$ & 23.4 & $0.003 * *$ & & \\
\hline Intervention group & $45.7(23.3)$ & $67.0(15.5)$ & 21.3 & $<0.00 I^{* *}$ & & \\
\hline Fatigue visual numeric & & & & & 0.007 & 0.584 \\
\hline Conventional group & $4.5(2.0)$ & $4.3(2.2)$ & -0.2 & 0.698 & & \\
\hline Intervention group & $4.1(1.5)$ & $4.4(2.1)$ & 0.3 & 0.703 & & \\
\hline Energy/fatigue & & & & & 0.018 & 0.393 \\
\hline Conventional group & I0.I (3.3) & $10.4(3.3)$ & 0.3 & 0.622 & & \\
\hline Intervention group & $9.8(2.1)$ & II.I (2.9) & 1.3 & 0.063 & & \\
\hline Pain visual numeric & & & & & 0.048 & 0.160 \\
\hline Conventional group & $4.3(2.5)$ & $3.9(3.3)$ & -0.4 & 0.483 & & \\
\hline Intervention group & $3.7(1.8)$ & $4.5(2.3)$ & 0.8 & 0.195 & & \\
\hline Pain severity/interference & & & & & 0.833 & $0.00 I^{* *}$ \\
\hline Conventional group & $10.0(3.8)$ & $9.0(4.0)$ & -1.0 & 0.225 & & \\
\hline Intervention group & $9.7(2.8)$ & $9.0(3.0)$ & -0.7 & 0.294 & & \\
\hline Shortness of breath visual numeric & & & & & 0.057 & 0.125 \\
\hline Conventional group & $0.9(1.8)$ & I.I (2.I) & 0.2 & 0.738 & & \\
\hline Intervention group & $2.0(2.3)$ & I.I (2.I) & -0.9 & 0.094 & & \\
\hline 8-item HAQ-disability & & & & & 0.000 & 0.982 \\
\hline Conventional group & I3.I (6.3) & $12.6(5.9)$ & -0.5 & 0.570 & & \\
\hline Intervention group & $12.2(5.7)$ & $11.7(6.0)$ & -0.5 & 0.383 & & \\
\hline Health distress & & & & & 0.010 & 0.529 \\
\hline Conventional group & $9.5(3.4)$ & $8.7(5.1)$ & -0.8 & 0.585 & & \\
\hline Intervention group & $7.5(3.8)$ & $7.7(2.2)$ & 0.2 & 0.757 & & \\
\hline PHQ-9 (depression) & & & & & 0.082 & 0.063 \\
\hline Conventional group & $8.0(5.9)$ & $7.6(5.8)$ & -0.4 & 0.753 & & \\
\hline Intervention group & $8.7(5.9)$ & $5.3(3.4)$ & -3.4 & $0.001 * *$ & & \\
\hline Social/role activities limitations & & & & & 0.160 & $0.008^{* *}$ \\
\hline Conventional group & II.I (5.I) & $10.9(6.0)$ & -0.2 & 0.813 & & \\
\hline Intervention group & $12.5(3.3)$ & $6.9(6.0)$ & -5.6 & $0.001 * *$ & & \\
\hline
\end{tabular}

Notes: $* P<0.05$. $* * P<0.01$.

Abbreviations: SD, standard deviation; HAQ, Health Assessment Questionnaire; PHQ, Patient Health Questionnaire. 


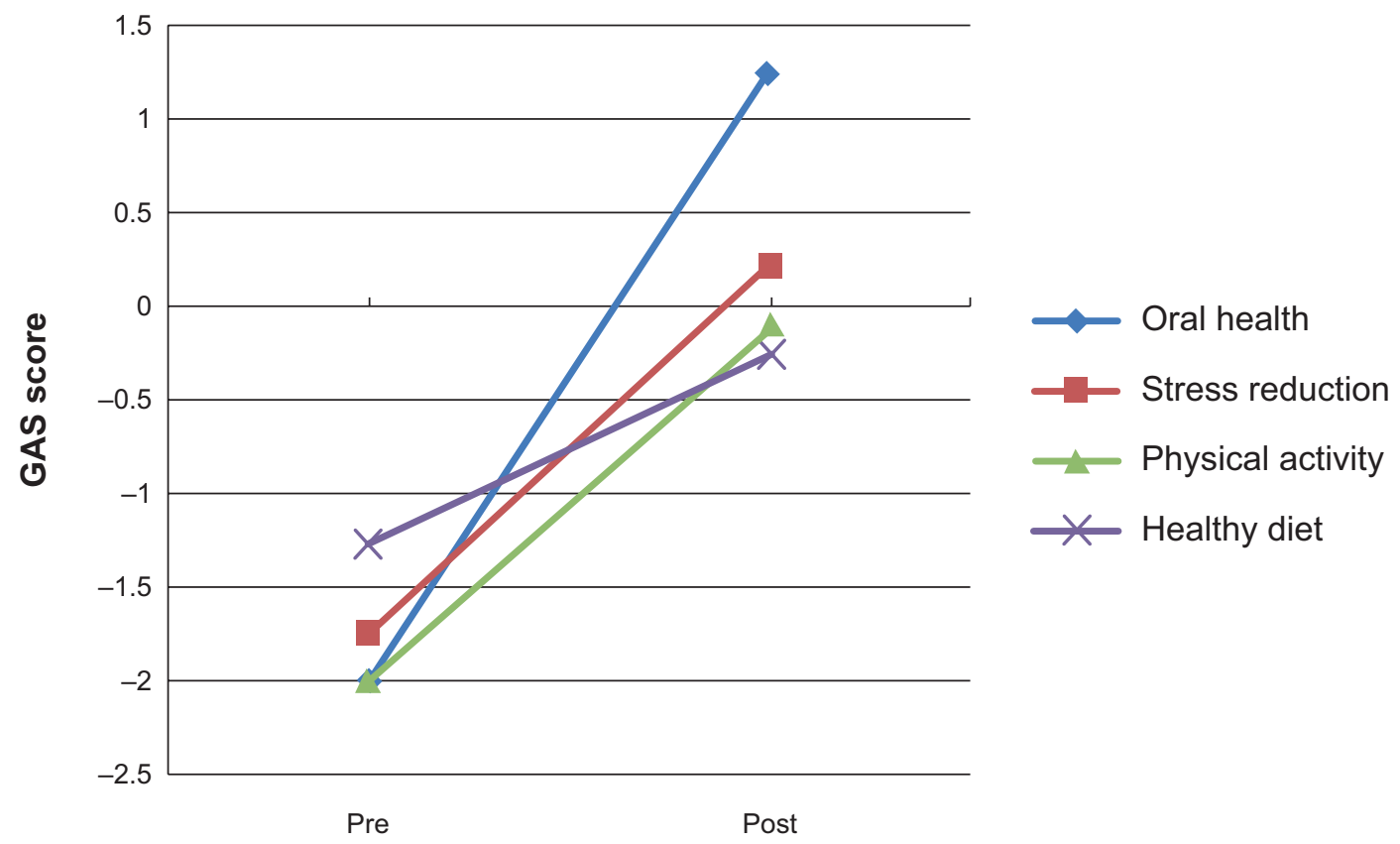

Figure 3 Changes of average GAS in intervention group $(n=22)$.

Abbreviation: GAS, Goal Attainment Scaling.

professionals in nursing homes to communicate with the residents. ${ }^{23}$ Chronic symptoms, like fatigue, pain, shortness of breath, and health distress were popular and rootbound in nursing home residents; ${ }^{23}$ hence, it might be difficult to change these symptoms in a relatively short intervention period. ${ }^{24}$

In the health coaching paradigm, the participant is considered resourceful and whole, not a chronic illness to be managed; ${ }^{25}$ thus, we developed a HCSMP that utilized goal setting, identified barriers, and used personal support systems. The success of this study is reliant not only on the capacity of the participants to engage in behavior change but also on the performance of the individual health coaches. According to the spirit of motivational interviewing, the therapeutic relationship is more like a partnership or companionship than expert/recipient roles. ${ }^{26}$ It is, therefore, essential that health coaches are supported in their role.

Using the GAS, it is interesting that oral health was the most achieved goal of the four goals. In our study, nursing home residents expressed great concerns about their oral health. Oral health has been recognized as one of the most important factors of older people's general health. ${ }^{23}$

Despite the dependence on nursing home staff because of the limited capabilities in daily activities, many older adults have been recognized for their active engagement in health coaching self-management approaches. ${ }^{8}$ Consistent with previous studies, the GAS might have contributed to improving the interest, attention, and achievement of the participants in this study; GAS was known as an individualized measure that has been used in older persons, including nursing home residents. ${ }^{27}$ As reported by previous studies,${ }^{28}$ the use of GAS might give participants in the intervention group positive feedback to improve individual outcomes because we had to meet face to face and give participants individual coaching to set individual goals during the intervention period. This means GAS acted as an intervention strategy as well as measuring the outcomes for the intervention group; ${ }^{29}$ hence, it might have acted as an intervention beginning with a request that participants set a specified number of goals in a personal goal questionnaire. It suggests that we should implement health coaching programs as a package containing coaching, goal setting, attainment, and adherence promotion. In addition, by respecting each participant's autonomy and resisting the urge to push against any resistance put up by them, we might have a better chance to reach positive outcomes. ${ }^{30}$

Especially, many of the barriers to physical activity identified by this population were difficult to overcome because they required greater social support, eg, for older people to walk more; they needed someone to accompany them. For those who were in a wheelchair, this is a very difficult problem to overcome. Thus, they set practical and somewhat limited goals, such as wheelchair movements or upper extremity activities. It is important that they set their own goals for themselves without any involvement or directions from health professionals or the researchers. 
Several implementation issues were identified during the 8 -week intervention period. The key issues are the rigorous routine of a nursing home and the dependency of residents; hence, when implementing a HCSMP in the current system for nursing homes, the procedure is complicated, time consuming, and costly. ${ }^{31}$ Closer integration of HCSMP into ongoing health service delivery may improve the efficiency of the training and support for health care providers. However, the lessons from this study are that adequate training budgets and adequate reimbursement of health care providers for their time and commitment will help with the sustained recruitment of program participants, the effective running of these types of programs and ultimately the outcomes.

Some limitations in our study should be mentioned. The low number of subjects and the exclusion of participants without moderate-severe cognitive impairment restrict the ability to generalize the findings. Furthermore, the study had a relatively short intervention period of 8 weeks, and it would be interesting to study the effects over a longer intervention period. This study is limited by a small sample size that was selected from a single geographic area. It is not representative of the nursing home population in terms of race, education, or socioeconomic status, thus limiting generalization. Future research should take this into consideration. Further prospective studies are needed with larger samples to fully evaluate health coaching self-management intervention for multifaceted lifestyle changes.

\section{Conclusion}

The HCSMP was effective in changing self-management behaviors and improving the perceived health status of older adults with multimorbidity in nursing homes. Given the increased number of nursing home residents, health coaching self-management intervention is likely to improve care outcomes based on a whole-of-facility approach that is highly intensive and supported by a trained staff. The intervention also assists nurses to take an active involvement in selfmanagement support and helps them to create effective quality of care strategies in nursing homes. Therefore, a health coaching self-management intervention is a feasible approach that may not only empower older adults with multimorbidity in nursing homes for their care, but it also offers qualified training and guidelines to nursing home staff, expanding their professional competence in clinical practice.

Further research is needed to develop and evaluate the long-term effects of a health coaching intervention to enhance self-management, health status, and quality of life, hospitalization, and global utilization measures for older adults with multimorbidity.

\section{Author contributions}

YP was responsible for study design. Both $\mathrm{HC}(60 \%)$ and YP (40\%) contributed data collection and analysis. Both HC $(50 \%)$ and YP (50\%) wrote the manuscript.

\section{Acknowledgments}

This research was supported by a grant from the Research Institute of Nursing Science of Seoul National University and Basic Science Research Program through the National Research Foundation of Korea, funded by the Ministry of Education, Science and Technology (810-20130022).

\section{Disclosure}

The authors report no conflicts of interest in this work.

\section{References}

1. Sevick MA, Trauth JM, Ling BS, et al. Patients with Complex Chronic Diseases: perspectives on supporting self-management. J Gen Intern Med. 2007;22 Suppl 3:438-444.

2. Marengoni A, Angleman S, Melis R, et al. Aging with multimorbidity: a systematic review of the literature. Ageing Res Rev. 2011; 10(4):430-439.

3. Ministry of Health, Welfare and Family Affairs in Korea. The Survey on the Actual Conditions of Older Person in Korea, Seoul; 2011.

4. Jordan JE, Briggs AM, Brand CA, Osborne RH. Enhancing patient engagement in chronic disease self-management support initiatives in Australia: the need for an integrated approach. Med J Aust. 2008; 189(10 Suppl):S9-S13.

5. Kennedy A, Gask L, Rogers A. Training professionals to engage with and promote self-management. Health Educ Res. 2005;20(5): 567-578.

6. Dennis SM, Zwar N, Griffiths R, et al. Chronic disease management in primary care: from evidence to policy. Med J Aust. 2008;188(8 Suppl): S53-S56.

7. Trappenburg J, Jonkman N, Jaarsma T, et al. Self-management: one size does not fit all. Patient Educ Couns. 2013;92(1):134-137.

8. Park YH, Chang H, Kim J, Kwak JS. Patient-tailored self-management intervention for older adults with hypertension in a nursing home. J Clin Nurs. 2013;22(5-6):710-722.

9. Hayes E, Karen KA. From the sidelines: coaching as a nurse practitioner strategy for improving health outcomes. J Am Acad Nurse Pract. 2007;19(11):555-562.

10. Berg J, Tichacek MJ, Theodorakis R. Evaluation of an educational program for adolescents with asthma. $J$ Sch Nurs. 2004;20(1): 29-35.

11. Hayes E, McCahon C, Panahi MR, Hamre T, Pohlman K. Alliance not compliance: coaching strategies to improve type 2 diabetes outcomes. J Am Acad Nurse Pract. 2008;20(3):155-162.

12. Marks R, Allegrante JP, Lorig K. A review and synthesis of research evidence for self-efficacy-enhancing interventions for reducing chronic disability: implications for health education practice (part II). Health Promot Pract. 2005;6(2):148-156.

13. Grimshaw JM, Eccles MP, Walker AE, Thomas RE. Changing physicians' behavior: what works and thoughts on getting more things to work. J Contin Educ Health Prof. 2002;22(4):237-243.

14. Huffman MH. HEALTH COACHING: a fresh, new approach to improve quality outcomes and compliance for patients with chronic conditions. Home Healthc Nurse. 2009;27(8):490-496; quiz 496-498.

15. Birtwhistle RV, Godwin MS, Delva MD, et al. Randomised equivalence trial comparing three month and six month follow up of patients with hypertension by family practitioners. BMJ. 2004;328(7433):204. 
16. Standford Patient Education Research Center. Chronic diesease selfmanagement program questionnaire code book. Palo Alto, CA: Standford Patient Education Research Center. Available from: http://med. stanford.edu/patienteducation/research/cdCodeBook.pdf. Accessed July 1, 2014.

17. Rushton PW, Miller WC. Goal attainment scaling in the rehabilitation of patients with lower-extremity amputations: a pilot study. Arch Phys Med Rehabil. 2002;83(6):771-775.

18. Cohen J. Statistical Power Analysis for the Behavioral Sciences. 2nd ed. Hillsdale NJ: Lawrence Erlbaum Associates; 1988.

19. Warner LM, Ziegelmann JP, Schuez BEC, Wurm S, Tesch-Romer C, Schwarzer R. The interplay of self-efficacy and social support as predictors of autonomy in older adults with multimorbidity: 24th Conference of the European Health Psychology Society, Cluj-Napoca, Romania, September 1-4, 2010. Oxon, UK: Taylor \& Francis Group; 2010.

20. Jensen B, Cohen-Mansfield J. How do self-care routines of nursing home residents compare with past self-care practices? Geriatr Nurs. 2006;27(4):244-251.

21. Tsai YF. Self-care management and risk factors for depressive symptoms among elderly nursing home residents in Taiwan. J Pain Symptom Manage. 2006;32(2):140-147.

22. Shultz JA, Crogan NL, Evans BC. Organizational issues related to satisfaction with food and food service in the nursing home from the resident's perspective. J Nutr Elder. 2005;24(4):39-55.

23. Park MJ, Suh E, Lee JM. Nursing staffs' experiences of managing medical needs of the elderly in Korean long-term care facilities. Korean Journal of Adult Nursing. 2013;25(4):409-421.
24. Bennett H, Laird K, Margolius D, Ngo V, Thom DH, Bodenheimer T. The effectiveness of health coaching, home blood pressure monitoring, and home-titration in controlling hypertension among low-income patients: protocol for a randomized controlled trial. BMC Public Health. 2009;9:456.

25. Grant AM. An integrative goal-focused approach to executive coaching. In: Stober DR, Grant AM, editors. Evidence Based Coaching Handbook: Putting Best Practices to Workfor Your Clients. New York: John Wiley \& Sons; 2006:153-192.

26. Rollnick S, Miller WR. What is Motivational Interviewing? Behav Cogn Psychother. 1995;23(04):325-334.

27. Gordon JE, Powell C, Rockwood K. Goal attainment scaling as a measure of clinically important change in nursing-home patients. Age Ageing. 1999;28(3):275-281.

28. Yip AM, Gorman MC, Stadnyk K, Mills WG, MacPherson KM, Rockwood K. A standardized menu for Goal Attainment Scaling in the care of frail elders. Gerontologist. 1998;38(6):735-742.

29. Yi A, Schaude B, Bonham S. Poster 106 the use of goal attainment scaling with veterans with traumatic brain injury and post-traumatic stress disorder. Arch Phys Med Rehabil. 2011;92(10):1722.

30. Butterworth SW. Influencing patient adherence to treatment guidelines. J Manag Care Pharm. 2008;14(6 Suppl B):21-24.

31. Goetzel RZ, Ozminkowski RJ. The health and cost benefits of work site health-promotion programs. Annu Rev Public Health. 2008;29:303-323.
Patient Preference and Adherence

\section{Publish your work in this journal}

Patient Preference and Adherence is an international, peer-reviewed, open access journal that focusing on the growing importance of patient preference and adherence throughout the therapeutic continuum. Patient satisfaction, acceptability, quality of life, compliance, persistence and their role in developing new therapeutic modalities and compounds to optimize

\section{Dovepress}

clinical outcomes for existing disease states are major areas of interest for the journal. This journal has been accepted for indexing on PubMed Central. The manuscript management system is completely online and includes a very quick and fair peer-review system, which is all easy to use. Visit http://www. dovepress.com/testimonials.php to read real quotes from published authors. 